\title{
Study on Pore and Fissure Structure Characteristics of Deep Soft Coal Rock
}

\author{
Minbo Zhang $\mathbb{D}^{1,2}$, Zhen Zhang $\mathbb{D}^{1},{ }^{1}$ Dangyu Zhang $\mathbb{D}^{2},{ }^{2}$ Delong Zou $\mathbb{D}^{3}{ }^{3}$ Jinlei Du $\mathbb{D}^{1}{ }^{1}$ \\ Zichao Wang $\left(\mathbb{D},{ }^{1}\right.$ and Chunxin Li ${ }^{1}$ \\ ${ }^{1}$ Xingfa School of Mining Engineering, Wuhan Institute of Technology, Wuhan 430073, China \\ ${ }^{2}$ Jizhong Energy Resources Co., Ltd., Xingtai 054000, China \\ ${ }^{3}$ Shenyang Research Institute of CCTEG, Shenyang 110016, China
}

Correspondence should be addressed to Zhen Zhang; zhangzhen_19971125@163.com

Received 20 June 2021; Accepted 16 August 2021; Published 31 August 2021

Academic Editor: Feng Du

Copyright (c) 2021 Minbo Zhang et al. This is an open access article distributed under the Creative Commons Attribution License, which permits unrestricted use, distribution, and reproduction in any medium, provided the original work is properly cited.

\begin{abstract}
The microscopic pore and fissure structure is the key factor affecting the exploitation, storage, and migration of coalbed methane and coal spontaneous combustion tendency. For further research of the microstructure of deep soft coal rock, such as pores and fissures, the coal samples from the Yangdong mining area were qualitatively and quantitatively analyzed in terms of morphological characteristics, pore shape, pore specific surface area, pore volume, and pore diameter by a scanning electron microscope (SEM) and a low-temperature liquid nitrogen adsorption experiment. The results show that there are three major categories and five minor categories of pores with different genetic types, including metamorphic pore, exogenous pore, and mineral pore, and there are endogenous fissures, exogenous tensile fissures, and exogenous shear fissures developed in the coal body. According to the results of the low-temperature liquid nitrogen adsorption experiment, the hysteresis curves of coal samples can be divided into two types. The I type curve produces a loop. There is a "hysteresis loop" which is obvious, and there is an inflection point that is not obvious. The pore system is mainly composed of open pores. The II type curve has no adsorption back line and no obvious inflection point. The pore structure is mainly composed of an impermeable hole closed at one end. The BET specific surface area of coal samples ranges from 0.2810 to $4.7569 \mathrm{~m}^{2} / \mathrm{g}$, with an average of $1.27984 \mathrm{~m} / \mathrm{g}$. The $\mathrm{BJH}$ pore volume ranges from 0.002864 to $0.007377 \mathrm{~cm}^{3} / \mathrm{g}$, with an average of $0.0041246 \mathrm{~cm}^{3} / \mathrm{g}$. The average $\mathrm{BJH}$ pore diameter of coal samples ranges from 4.3935 to $20.1501 \mathrm{~nm}$, with an average of $16.0313 \mathrm{~nm}$. The pore specific surface area of coal is mainly contributed by micropores, and the transition pores contribute the most to pore volume. The distribution of pore volume in each pore section of a coal sample has the rule that the transition pore is larger than the micropore, and the micropore is larger than the mesopore, and the maximum ratio is $66.2 \%$. The distribution of pore specific surface area has the rule that the micropore is larger than the transition pore, and the transition pore is larger than the mesopore. The maximum ratio is $91.2 \%$.
\end{abstract}

\section{Introduction}

Coal is a kind of porous medium material, and its microscopic pore structure determines the adsorption, desorption, diffusion, seepage, and mechanical properties of coal. $[1,2]$ The pore and fissure structure of a coal body has a significant influence on the exploitation, storage, migration, and spontaneous combustion tendency of coal, and it is also a key factor affecting the extractability of coalbed methane $[3,4]$. As early as the 1960s, domestic and foreign scholars have begun to study the micropore structure of coal. Gan et al. believes that with the demand for energy and the development and utilization of coal and coalbed methane, people pay more and more attention to the study of coal pore structure [5]. The research methods of domestic and foreign scholars on the distribution characteristics of coal's microstructure and morphological development, pore and fracture types, and pore volume and specific surface area mainly include observation description and physical tests [6]. The observation description method mainly includes 
macrodescription and imaging of coal samples with an optical microscope, while common physical test methods include the densitometer algorithm, the mercury injection method (MIP), the low-temperature nitrogen or $\mathrm{CO}_{2}$ adsorption method, the scanning electron microscope (SEM), the nuclear magnetic resonance method, and the microscopic CT scanning method [7-9].

$\mathrm{Li}$ et al. [10] studied the relationship between the pore structure characteristics and structural deformation of tectonic coal in the Hancheng mining area using the microscopic CT test, and the study showed that cataclastic coal had the best pore connectivity and permeability, while mylonite coal had the worst. Meng et al. [11] studied Dongqu coking coal by using the microscopic CT and mercury injection test, and they obtained its pore diameter and morphology and other characteristics and believed that micropores were the main cause of poor permeability and connectivity. Thompson et al. and Kueper et al. [12, 13] first studied the porous material and calculated its fractal dimension. Wang et al. [14] studied the influence of coalification on the pore structure of the middle and high rank coal, and they found that micropores and transition pores accounted for the largest proportion of volume and specific surface area in middle and high rank coal. With the increase of coal rank, the fractal dimension of micropores gradually increased. Nie et al. [15] labeled the pore types in SEM images of coals with different metamorphic degrees. According to Mahamud's research [16], when the pressure of mercury injection is greater than $10 \mathrm{Mpa}$, the coal sample will produce a compression effect and destroy the coal's primary pore system. Cai et al. [17] used a small-angled ray combined with a scanning electron microscope to study and find out if the coal pores are mostly spheroid in low coal rank and ellipsoid in high coal rank. Klimenko et al. [18] used the conditional moment model to study the fractal characteristics of transportation, storage, and adsorption processes in the pores of $\mathrm{CO}_{2}$ porous media. $\mathrm{Li}$ et al. [19] adopted SEM, lowtemperature liquid nitrogen adsorption methods, and $\mathrm{CO}_{2}$ adsorption methods for 8 kinds of coals with different metamorphic degrees to analyze parameters such as pore volume, pore diameter, specific surface area, and pore shape, and they obtained the heterogeneity of the pore morphology of coals with different ranks. Jiang et al. [20] studied the pore characteristics of structural coal and divided the lowtemperature liquid nitrogen adsorption loop lines of coal samples into three categories. It is considered that there are four kinds of pores in coal: cylindrical pores with openings at both ends, cylindrical pores with openings at one end, ink bottle pores, and slit flat pores. Sun, Li and Wang, and Li et al. [21-23] also conducted low-temperature liquid nitrogen adsorption experiments under different metamorphic coals, different temperatures, different coal body structures, and different coal mines, so as to study the pore structure, pore volume and pore diameter distribution, and adsorption characteristics of coals under different conditions.

The pore-fissure structure of coal rock is closely related to coal seam mining and gas extraction, and it has a certain influence on coal spontaneous combustion. The pore-fissure structure in deep soft coal rock is extremely complex, and the pore size distribution varies from millimeter to nanometer. The different pore sizes control the adsorption, apportionment, diffusion, and seepage of coalbed methane. The traditional scanning electron microscope method only qualitatively studies the pore and crack parameters on the polished surface of a coal sample, but it cannot deeply study the internal pore structure of coal, which has limitations. In this paper, the method of SEM and low-temperature liquid nitrogen adsorption experiment is adopted. It is of great significance to the coalbed methane resource evaluation, exploration, and development for a qualitative and quantitative characterization of the innovative ways of combining different scales of deep soft coal rock micropore structure research and analysis of the changing rule of the specific surface area and pore volume of coal and the pore size distribution of laws and so on.

\section{Experimental Samples and Methods}

The coal sample in this experiment is taken from the Yangdong well field of the Fengfeng coalfield, which is located in the east wing of the middle part of the Fengfeng coalfield. The coal quality belongs to the section of coking coal, thin coal, and lean coal in the metamorphic zone of the Fengfeng coalfield. The industrial analysis of raw coal quality is shown in Table 1:

According to the relevant standards of "GB/T482-2008 Coal Sample Method for Coal Seam" and "SY/T6154-1995 Determination of Static Nitrogen Adsorption Capacity by Rock Specific Surface and Pore Diameter Distribution," the no. 2 coal (large coal) of the Permian Shanxi Formation in Yangdong Mine was collected as experimental coal samples, and the collected coal samples were sealed and stored in sealed bags with labels and transported to the laboratory.

2.1. Scanning Electron Microscope Observation Method. According to the test requirements of the samples in the laboratory, the collected large coal samples are cut at a slow speed. The size of the cut is generally about $1 \mathrm{~cm} \times 1 \mathrm{~cm} \times$ $1 \mathrm{~cm}$, which is a relatively regular cube. If there is secondary damage to the coal in the cutting process, the sample will be scrapped. One side of the qualified small sample is ground and disassembled; that is, the gauze is used for smooth and slow grinding, respectively. The side after disassembling is selected as the observation surface, and its surface is purged for clean treatment, and then dried. Then, conductive treatment (the observation surface is plated with a conductive layer) is conducted for experimental observation. The experimental instrument utilized here was the JSM-5510LV scanning electron microscope from Japan Electron Optics Laboratory Co., Ltd., as shown in Figure 1. The instrument resolution was $3.2 \mathrm{~nm}$, and the magnification was continuously adjustable from 18 to 300,000 . The surface of the sample was observed by secondary electronic imaging, and the apparent morphology and pore-fissure structure of the sample were analyzed. 
TABLE 1: Raw coal industry analysis results.

\begin{tabular}{lccccccc}
\hline Coal sample & Mad (\%) & Ad (\%) & Vdaf $(\%)$ & Std $(\%)$ & Qgrad $(\mathrm{MJ} / \mathrm{kg})$ & GR.I & CR.C (1-8) \\
\hline \multirow{2}{*}{ Large coal } & $0.54 \sim 2.08$ & $11.97 \sim 38.34$ & $16.78 \sim 33.75$ & $0.20 \sim 0.70$ & $20.74 \sim 31.93$ & $3 \sim 79$ & $4 \sim 7$ \\
& 1.31 & 25.16 & 25.27 & 0.32 & 26.34 & 41 & 6 \\
\hline
\end{tabular}

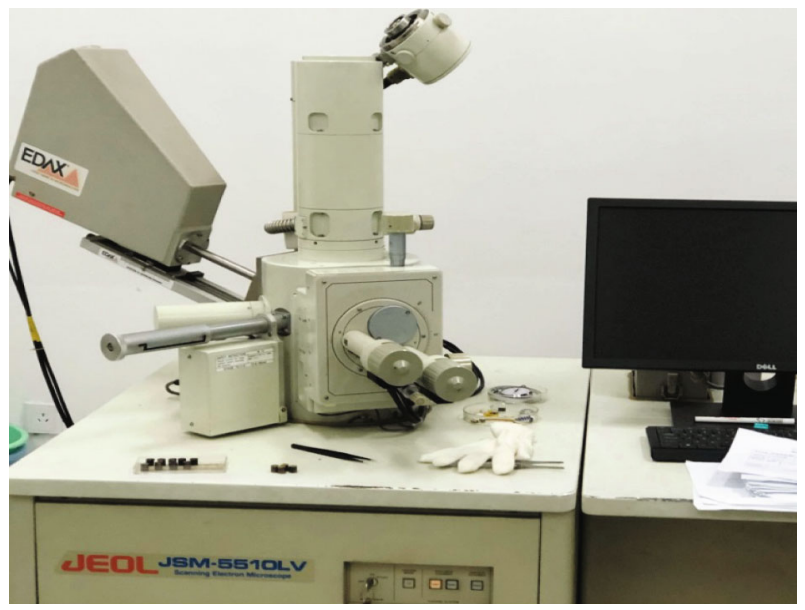

Figure 1: JSM-5510LV scanning electron microscope.

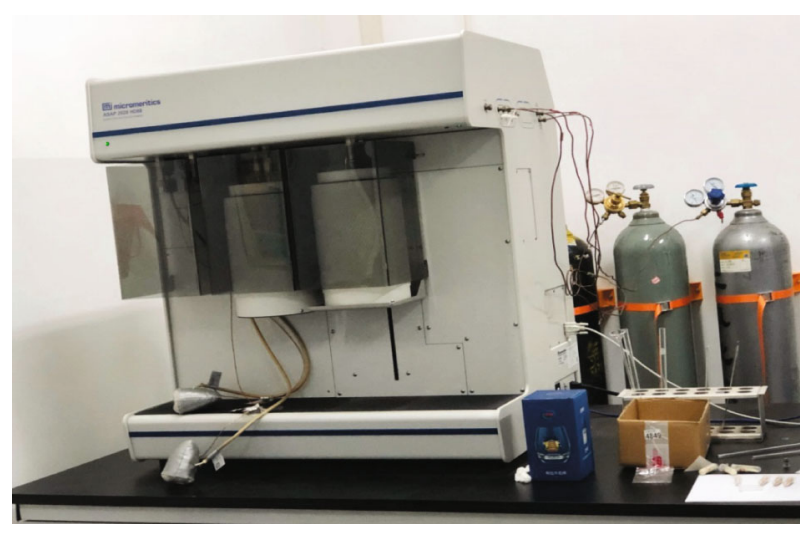

Figure 2: ASAP-2000 automatic surface and aperture analyzer.

2.2. Low-Temperature Liquid Nitrogen Adsorption Method. According to the requirements of the experimental test, the large coal samples collected were crushed with a crusher in the laboratory, and then the crushed coal samples with a particle size of 60 to 80 mesh were screened out by a standard sieve. The prepared coal samples were put into a $105^{\circ} \mathrm{C}$ electric heating blast drying oven to dry, and then they were bottled and sealed for storage for experimental use. The experimental instrument utilized here was the ASAP-2000 automatic specific surface and aperture analyzer produced by Micromeritics Instrument Co., Ltd., as shown in Figure 2. The test was carried out according to the national standard "Determination of specific surface area of solid substance by gas adsorption BET method" (GB/T19587-2017). The instrument has high testing accuracy, the specific surface area analysis range is from $0.0005 \mathrm{~m}^{2} / \mathrm{g}$ to none, the pore diameter analysis range is 0.5 to $500.0 \mathrm{~nm}$, and the pore volume minimum can detect
$0.0001 \mathrm{~cm}^{3} / \mathrm{g}$. The nitrogen adsorption method is used to measure the pore structure distribution characteristics of the coal sample, such as the specific surface area, pore diameter, and pore volume.

\section{Analysis of Microstructure Characteristics of Coal under Scanning Electron Microscope}

3.1. Analysis of Pore Characteristics of Coal Body. The pore and fissure results observed by a large number of scanning electron microscopy (SEM) analyses are shown in Figures 3 and 4 . The coal samples are observed at different magnification ratios, and the pore and fissure characteristics of each coal sample can be clearly seen.

According to the scanning electron microscopy results of the coal samples in Figure 3, five types of pores are developed in the coal samples, including the granular pore, the breccia pore, the friction pore, the intergranular pore, and the air vent. The coal body as a whole is a collection of broken particles; the structure is loose, the whole coal body is flaky, the granular pore is attached to the surface of the coal body, and they have different shapes and sizes, irregular shapes, and relatively developed pore structures. Most of the pores are filled and stacked with minerals, including granular pores (Figure 3(a)), breccia pores (Figures 3(a) and $3(\mathrm{~b})$ ), and intergranular pores (Figure 3(c)). The coal body is damaged by the weak tectonic stress field or external factors, and it forms a sharp corner shape with a relatively regular shape. There is basically no displacement between the holes, and the connectivity is good. The holes formed between the breccia (i.e., the breccia holes) are exogenous holes. The pore diameter generally ranges from $2 \mu \mathrm{m}$ to $10 \mu \mathrm{m}$, which is usually found in cataclastic coal. There are some clastic minerals filling in the pore, but it will not seriously block the pore fissure and has a certain permeability. A fragmentary hole is a kind of exogenous hole formed after being damaged by strong tectonic stress, and the shape of the crushed grain is mostly a sheet, block, or semicircle. It is small in volume and easy to accumulate. It is a displacement hole formed between the crushed grains and has good connectivity. The pore diameter range is generally 0.5 to $5 \mu \mathrm{m}$, and it is mostly found in cataclastic coal and crushed coal. Because severe fissures will block the pore and fissure, it has a certain influence on the permeability of a coal reservoir. Intergranular pore is the pore between the mineral grains, and it is a mineral pore. The pore diameter is generally micron sized, which is less developed in the coal body and has little influence on the permeability of a coal reservoir.

It can also be seen from the figure that the structure on the surface of the coal body is becoming denser, with fewer fissures and macropores. The pores are more elliptical and 

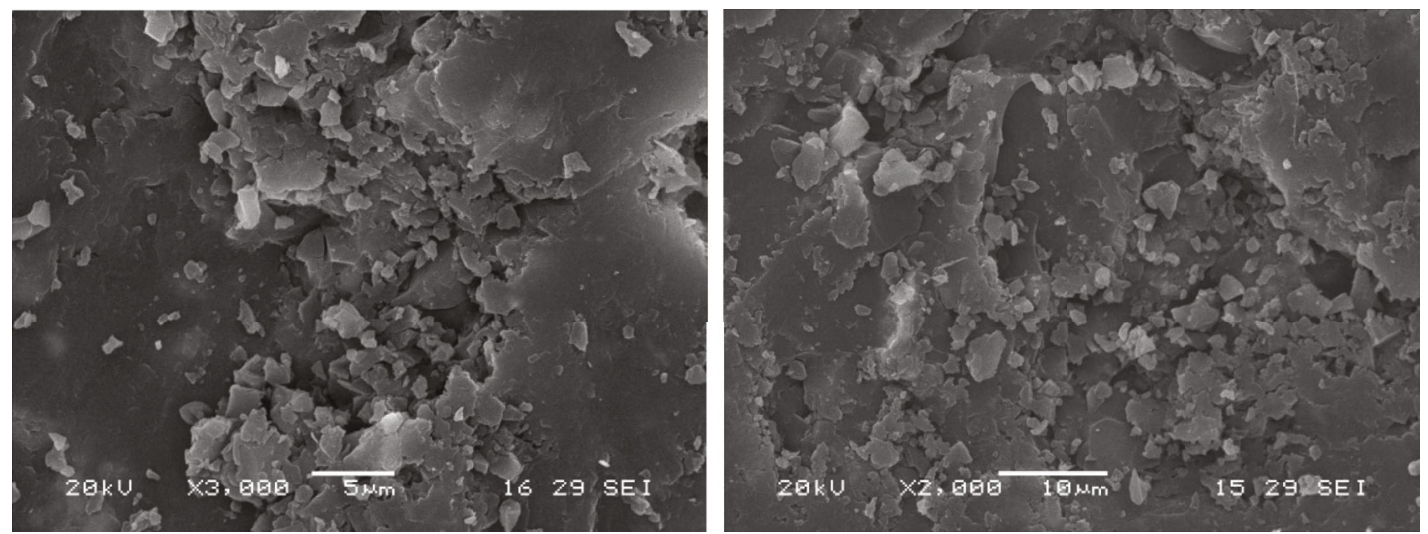

(a) Granular hole and breccia hole

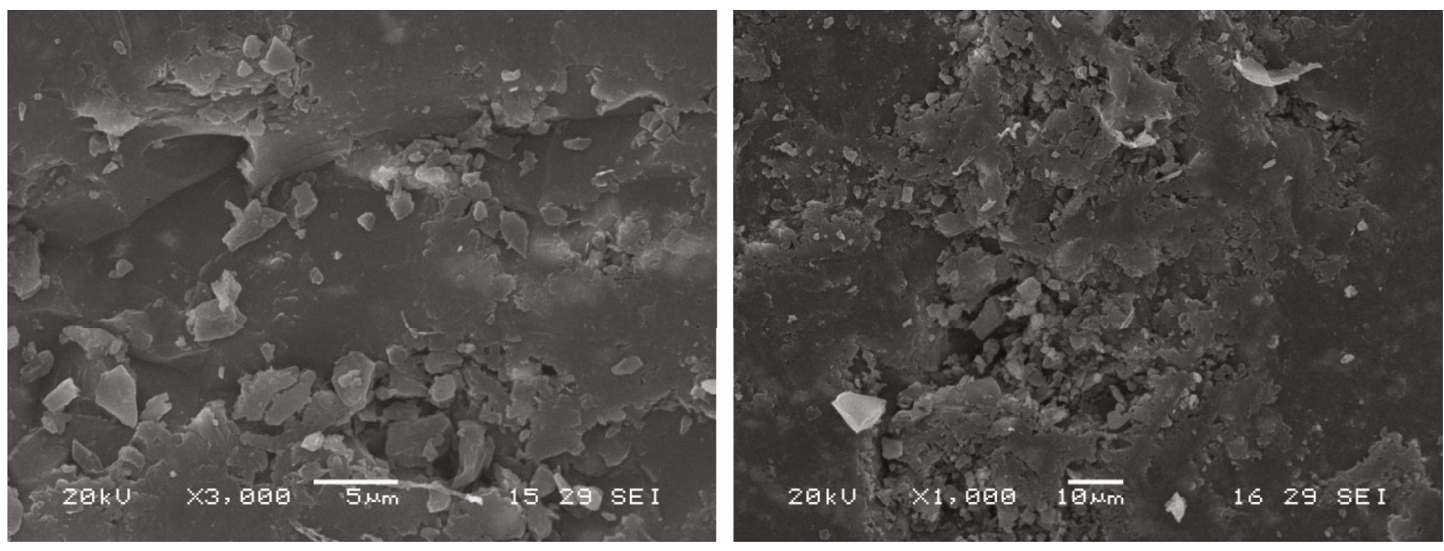

(b) Breccia hole and friction hole

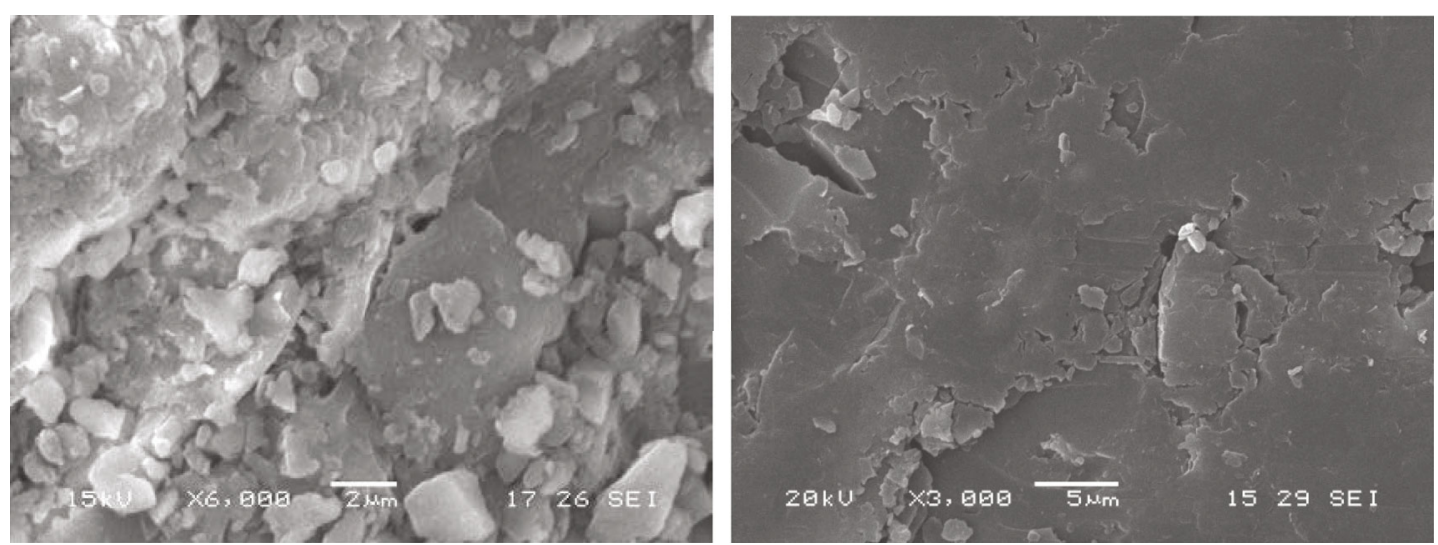

(c) Intergranular pore and friction hole

Figure 3: Continued. 

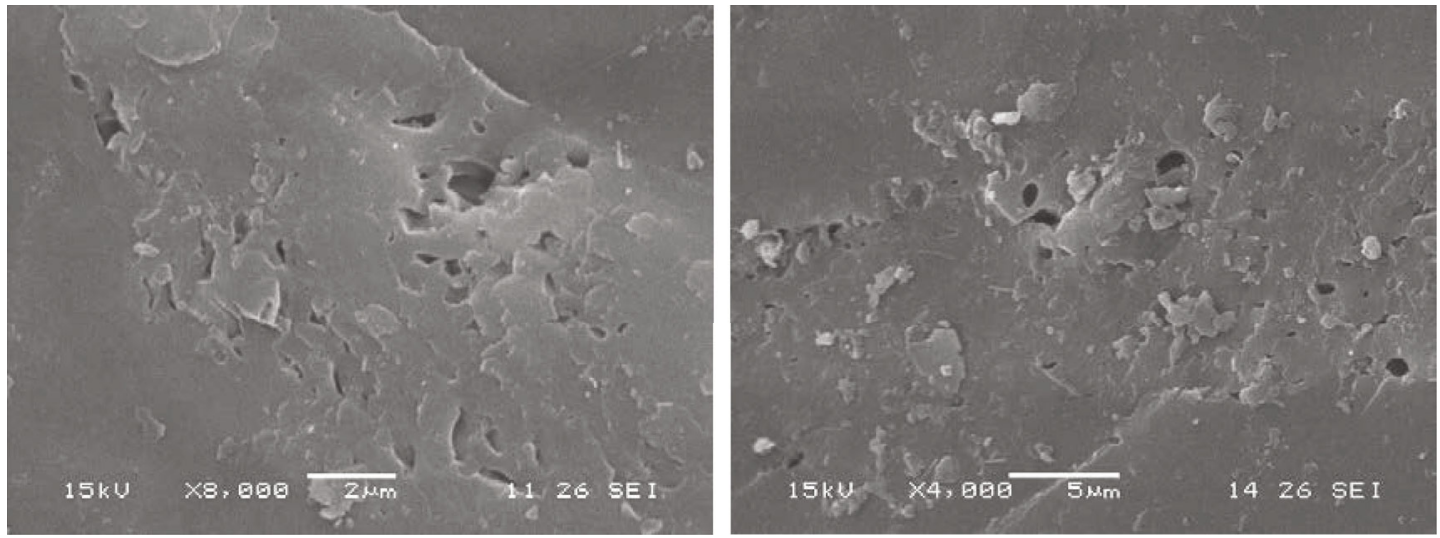

(d) Air vent

Figure 3: Pore characteristics under a scanning electron microscope.

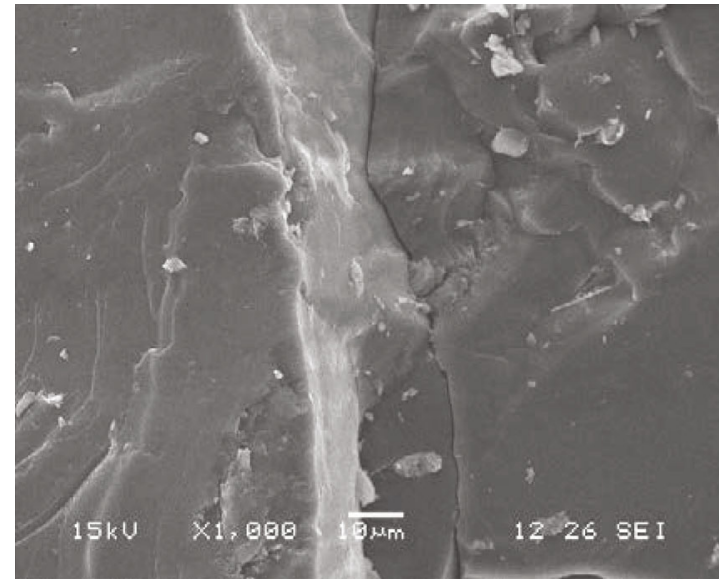

(a) Endogenous fissure

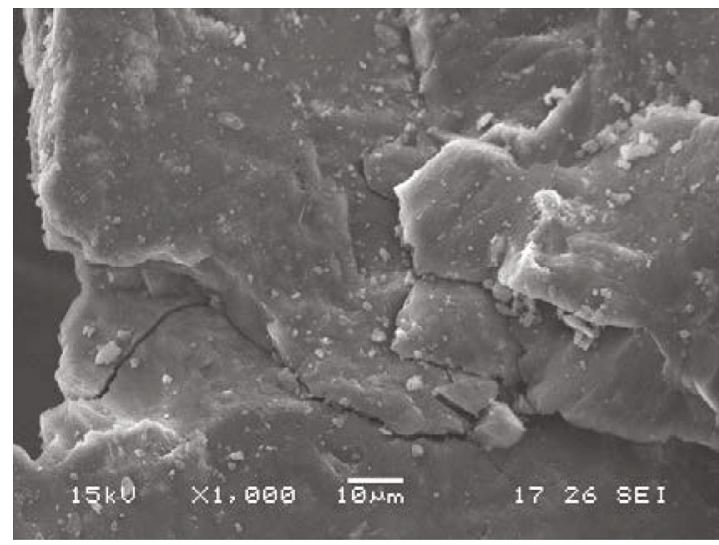

(c) Exogenous shear fissure

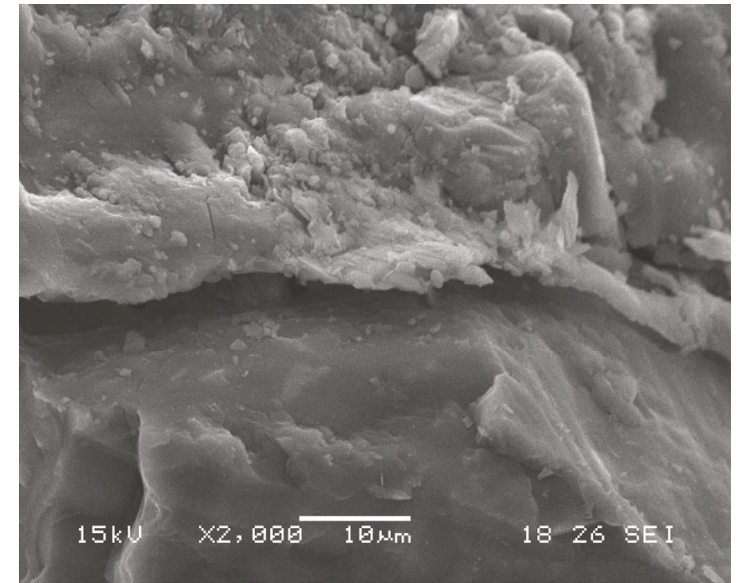

(b) Exogenous tensile fissure

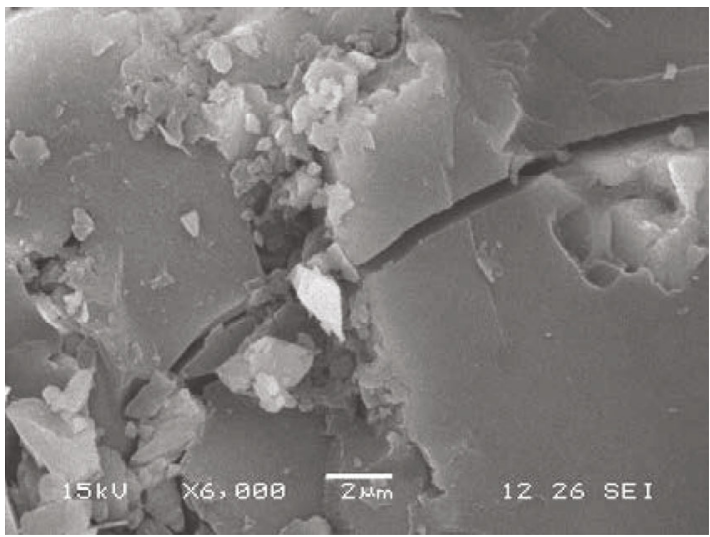

(d) Exogenous tensile fissure are filled with debris

FIgURE 4: Fissure characteristics under scanning electron microscope.

angular, the size is not uniform, there are few endogenous fissures, and primary bedding and fine bedding are rare. The surface of the coal sample is smooth, the structure development is relatively complete, there are few and thin holes on the surface, the connectivity between holes is poor, and the fissures are not developed. Friction pores (Figures 3(b) and 3(c)) and air vents (Figure 3(d)) were developed. Under the action of compressive stress, and due to friction or the sliding movement between the coal face and the surface, there is the formation of grooves, round lines, and long triangular or linear holes (namely friction holes) that are exogenous holes. The pore diameters vary from 1 to $2 \mu \mathrm{m}$ to dozens of microns. The pores are partially connected, which has a certain effect on the migration of 
coalbed methane. The pores exist in cataclastic coal and crushed coal. The air vent is a kind of metamorphic pore, which is mostly round, oval and tubular with smooth edge and formed by "gas generation" and "gas accumulation" due to coalification in the coal-forming period. The common stomata size is 0.1 to $3 \mu \mathrm{m}$, the development is more concentrated, about $1 \mu \mathrm{m}$ is more common, the stomata are independent of each other, the connectivity between the pores is not good, and the pores are developed in both primary coal and structural coal.

3.2. Analysis of Coal Fissure Characteristics. The fissure in the coal body is due to the coal seam in the coal-forming period by the nature of various stresses, such as tectonic stress and geological stress, resulting in the coal body fissure, section opening or fissure, and other non-closed-state fissure phenomena. Research on coal microfissures began last century, but research progress is relatively slow. It was not until the 1960s, when Ammosov and Eremin [24], both scholars of the former Soviet Union, put forward their ideas in the book "Fissures in Coal." Since then, the research on coal body fissures gradually became mature. Later, the term "cleat" was proposed to describe endogenous fissures, and cleat can be divided into facet cleat and end cleat [25]. On the basis of previous research, this paper also divides the fissures in the coal into two types: endogenous and exogenous.

As can be seen from Figure 4, there are endogenous fissures and exogenous fissures developed in the coal samples, and their morphology, size, and genesis are different. In the endogenous fissure, coal is densely developed, with few fillings and no scratches on the surface, which are relatively flat and have tensile characteristics (as shown in Figure 4(a)). Fills in cleats are generally autogenic minerals and rarely fill broken coal particles. Under certain tectonic action, dislocation or extrusion occurs between coal bodies, resulting in fissures or openings, and exogenous tensile fissures and shear fissures can be seen (as shown in Figures 4(c) and 4(d)). Due to the effect of tensile stress, the exogenous tensile fissure has a large opening, appearing as a narrow and long opening (as shown in Figure $4(\mathrm{~d})$ ). There is no scratch on the surface, and some debris will be filled in the fissures, with cracks ranging from a few microns to dozens of microns. Exogenous shear fissures rupture due to the action of shear force, showing staggered small fissures and long extension. The fissure has a small opening and is basically closed (as shown in Figure 4(c)). Most fissures are imbricated or stepped, and some are also X-shaped, with good ductility and debris filling.

\section{Analysis of Low-Temperature Liquid Nitrogen Adsorption Experiment Results}

The pore structure of coal is complex, and the pore diameter distribution varies from millimeter to nanometer. Therefore, the study of the pore structure of coal not only needs qualitative characterization but also needs to be combined with quantitative calculation to be more accurate. The above SEM results are used to qualitatively characterize the morphological characteristics of pore fissures on the surface of a coal body. The observed coal body morphological characteristics were relatively rough. The characteristics of micron and millimeter pores and fractures in coal samples can be clearly observed, but the nanosized pores cannot be detected. Therefore, the low-temperature liquid nitrogen adsorption experiment can be used to characterize the finer pore structure and morphological characteristics in coal.

4.1. Isothermal Adsorption Curve Analysis. Isotherma adsorption curve can well reflect the surface adsorption characteristics of coal samples, and pore morphology characteristics of experimental coal samples and pore diameter distribution which plays a major role in adsorption can be seen from the adsorption curve and desorption loop. The adsorption isotherm of each coal sample is shown in Figure 5.

The International Union of Pure and Applied Chemistry (IUPAC) classify the isotherm adsorption curve into six types [26]. Compared with the six adsorption isotherms, the nitrogen adsorption isotherm of coal samples tends to belong to the IV adsorption isotherm as a whole, but it is not the same as it. The overall adsorption curve shows an upward trend, and the adsorption curve is lower, while the desorption curve is higher. When the relative pressure is greater than 0.9 , the curve rises steeply, and the adsorption volume increases sharply. The curves show that at the beginning, the single-layer adsorption transitions to multilayer adsorption at the low pressure stage. As the relative pressure continues to increase, multilayer adsorption begins to appear, and the adsorption amount gradually increases until the multilayer adsorption gradually forms, and the adsorption layer is infinite when the saturated vapor pressure is reached. In the middle and high pressure stage (the relative pressure is greater than 0.5), the separation phenomenon of the adsorption curve and the desorption curve gradually appears, and the hysteresis loop is produced, namely, the hysteresis loop. The appearance of the adsorption hysteresis ring is caused by capillary condensation on the surface of coal under high pressure (the relative pressure is greater than 0.9 ).

It can be seen from the hysteresis loop of the coal sample in this experiment that its hysteresis loop type does not strictly belong to the specific type divided by IUPAC. Each type of adsorption hysteresis loop represents different pore structures and reflects the adsorption capacity and air permeability of coal. Referring to the study of adsorption experiments on a large number of coal samples by Chen and Tang [27], the adsorption isothermal hysteresis curve characteristics of coal samples in this experiment were observed and compared, and the adsorption isothermal hysteresis curves were divided into two types:

(1) I type: nos. 1, 2, 3, and 4 coal samples are representative, the normal type curve produces a loop, the desorption curve and the adsorption curve do not completely coincide, the curve "hysteresis loop" is obvious, and the inflection point is not obvious, indicating that there is no "ink bottle" like hole in the coal sample. The adsorption curve and desorption 

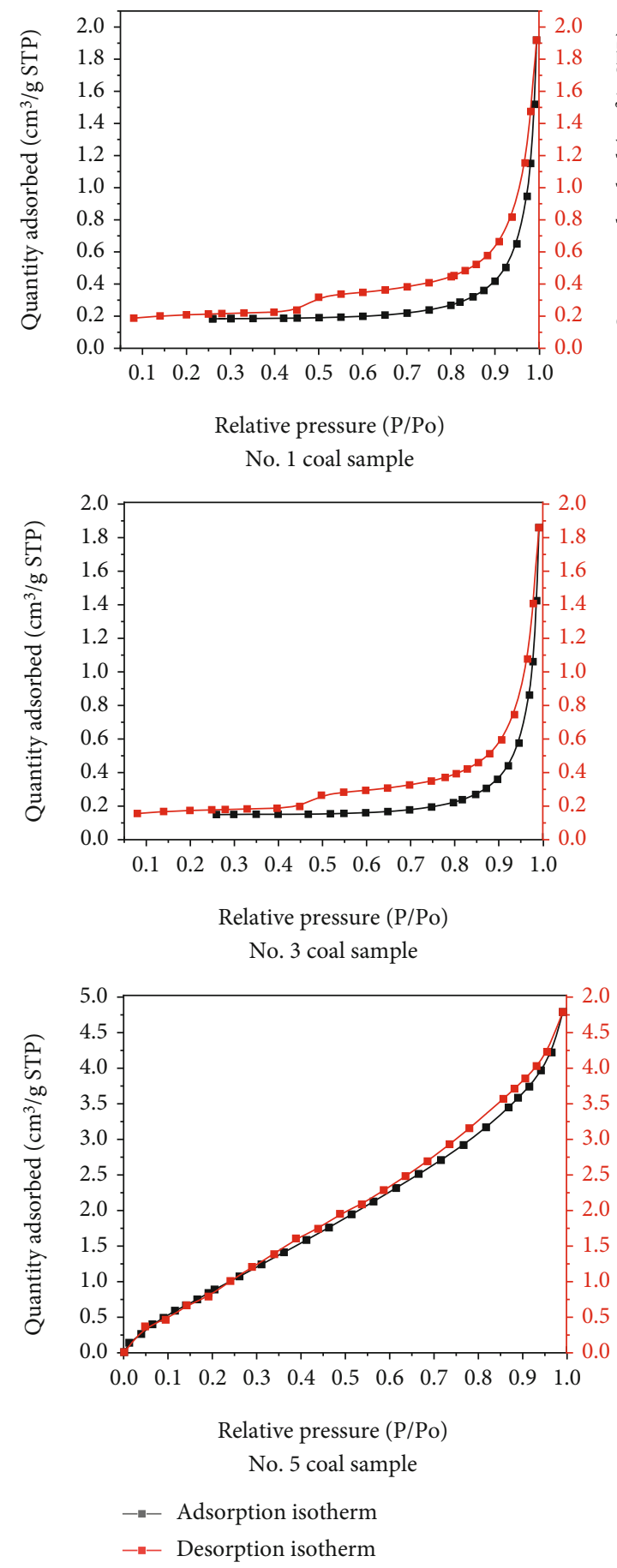
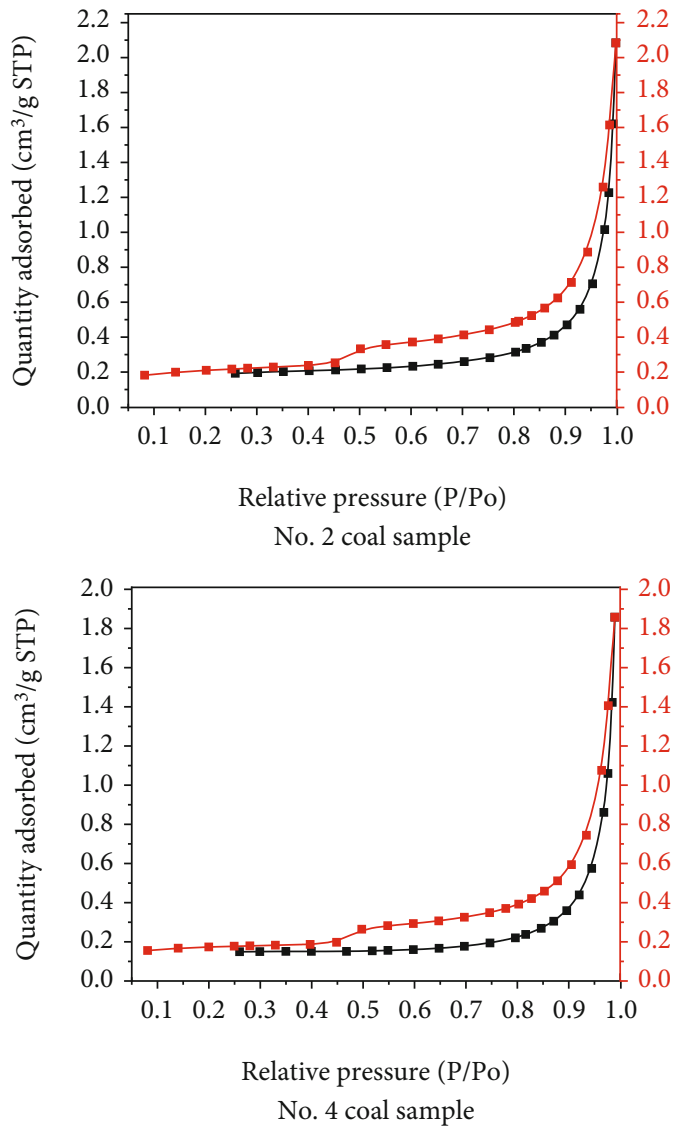

No. 4 coal sample

FIGURE 5: Adsorption isotherm of coal sample.

curve basically overlap at low and high relative pressure, and the inflection point occurs when the relative pressure is about 0.5 . In the region of 0.45 to 0.95 , the capillary condensation phenomenon occurs in the coal body, and the "hysteresis loop" is generated, which is because the pressure required for the capillary condensation of the coal body is less than that of evaporation. It shows that there are closed holes at one end in the low pressure and high pres- sure stages, which mainly include cylindrical holes, parallel plate holes, wedge-shaped holes, and tapered holes at one end. In the middle and high pressure stage, the pore system is mainly composed of open pores, including cylindrical pores at both ends and parallel plate pores at four sides, and part of slit pores. Such pore structure is conducive to the migration of coalbed methane, and has good permeability and connectivity 
TABLE 2: Pore structure parameters of coal samples.

\begin{tabular}{lccccc}
\hline $\begin{array}{l}\text { Coal } \\
\text { sample }\end{array}$ & $\begin{array}{c}\text { BET surface area } \\
\left(\mathrm{m}^{2} / \mathrm{g}\right)\end{array}$ & $\begin{array}{c}\text { BJH surface area } \\
\left(\mathrm{m}^{2} / \mathrm{g}\right)\end{array}$ & $\begin{array}{c}\text { Single point total pore volume } \\
\left(\mathrm{cm}^{3} / \mathrm{g}\right)\end{array}$ & $\begin{array}{c}\text { BJH pore volume } \\
\left(\mathrm{cm}^{3} / \mathrm{g}\right)\end{array}$ & $\begin{array}{c}\text { BJH average pore width } \\
(\mathrm{nm})\end{array}$ \\
\hline 1 & 0.3699 & 0.6433 & 0.002967 & 0.002942 & 18.2940 \\
2 & 0.4405 & 0.7358 & 0.003224 & 0.003252 & 17.6790 \\
3 & 0.2810 & 0.5686 & 0.002865 & 0.002864 & 20.1501 \\
4 & 0.5509 & 0.8529 & 0.004229 & 0.004188 & 19.6399 \\
5 & 4.7569 & 6.7164 & 0.007375 & 0.007377 & 4.3935 \\
Average & 1.27984 & 1.9034 & 0.004132 & 0.0041246 & 16.0313 \\
\hline
\end{tabular}

(2) II type: the no. 5 coal sample is representative, the normal type curve does not produce the adsorption back line, the desorption curve and the adsorption curve almost completely coincide, and the hysteresis phenomenon is not obvious, i.e., there is no obvious inflection point; this is because this kind of coal sample coal capillary condensation and evaporation required pressure that is basically equal. This shows that the pore structure of this kind of coal sample is mainly composed of impermeable pores with one end closed, including cylindrical holes, parallel plate holes, wedge-shaped holes, and tapered holes with one end closed. The pore connectivity is poor, which is not conducive to the exploitation and migration of coalbed methane. The poor connectivity between pores is not conducive to the exploitation and migration of coalbed methane

4.2. Specific Surface Area and Pore Volume Analysis. As a solid material of porous medium, coal's specific surface area is a powerful index to show the adsorption capacity of coal seam, and the adsorption capacity of coal presents a positive correlation with the change of the specific surface area. The specific surface area results obtained by different calculation models are also different. The specific surface area obtained by the BET calculation model is the most common method. In this experiment, the BET equation [28] based on the multimolecular layer adsorption theoretical model is used to characterize the specific surface area:

$$
\frac{1}{W\left[\left(p_{0} / p\right)-1\right]}=\frac{1}{W_{m} C}+\frac{C-1}{W_{m} C}\left(\frac{p}{p_{0}}\right)
$$

where $W$ is the weight of adsorbed gas at the relative pressure $\left(P / P_{0}\right) ; W_{m}$ is the weight of adsorbed gas covered by a single surface; $P / P_{0}$ is the adsorption relative pressure; $P$ is the equilibrium partial pressure of adsorbed mass; $P_{0}$ is the saturated vapor pressure of the adsorbent; $C$ is the BET constant, which is related to the adsorption energy of the first adsorption layer.

In physical adsorption, the adsorption between solid and gas is dependent on the intermolecular gravity and occurs. The molecules that have been adsorbed still have gravity; so, on top of the first layer of adsorption, they can also adsorb a second layer, a third layer ..., that is, multimolecular layer adsorption. Pore volume (also called pore volume) mainly shows the total pore volume per unit mass. Table 2

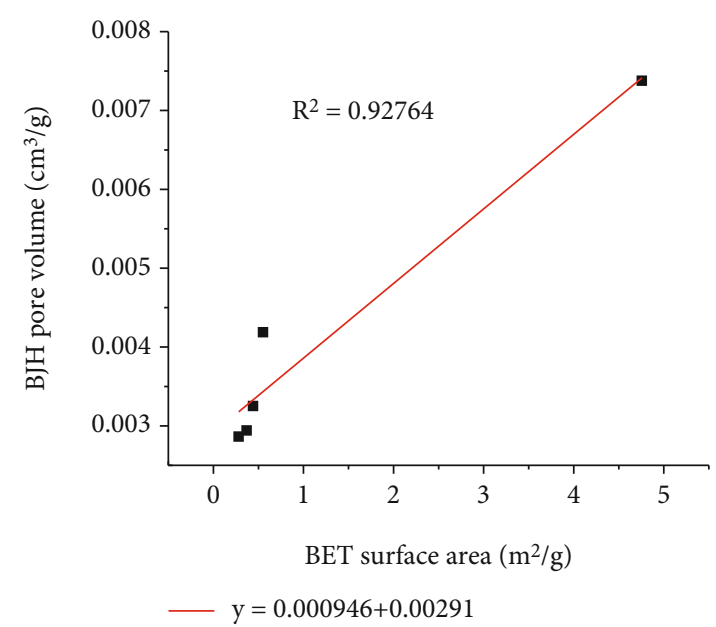

FIgURE 6: BET specific surface area and BJH pore volume fitting curve.

shows the distribution characteristics of pore structure parameters of coal samples obtained under the lowtemperature liquid nitrogen adsorption experiment.

The results show that the BET specific surface area of coal samples ranges from 0.2810 to $4.7569 \mathrm{~m}^{2} / \mathrm{g}$, with an average of $1.27984 \mathrm{~m}^{2} / \mathrm{g}$. The specific surface area of $\mathrm{BJH}$ ranges from 0.5686 to $6.7164 \mathrm{~m}^{2} / \mathrm{g}$, with an average of $1.9034 \mathrm{~m}^{2} / \mathrm{g}$. The BJH specific surface area is larger than that of BET on the whole, but the changing trend remains consistent. The total pore volume of the single point method of a coal sample ranges from 0.002865 to $0.007375 \mathrm{~cm}^{3} / \mathrm{g}$, with an average of $0.004132 \mathrm{~cm}^{3} / \mathrm{g}$. BJH pore volume ranges from 0.002864 to $0.007377 \mathrm{~cm}^{3} / \mathrm{g}$, with an average of $0.0041246 \mathrm{~cm}^{3} / \mathrm{g}$. Generally speaking, the difference between the two is very small. The BJH average pore diameter of a coal sample varies greatly from $4.3935 \mathrm{~nm}$ to $20.1501 \mathrm{~nm}$, with an average of $16.0313 \mathrm{~nm}$.

Figure 6 is the fitting curve of the relationship between specific surface area and pore volume. It can be seen that there is a positive correlation between specific surface area and pore volume, and both specific surface area and pore volume of coal samples in the mining area are small.

Figure 7 shows the pore specific surface area and pore volume increment diagram under different pore diameters. The relation diagram of the pore specific surface area and pore diameter shows that the curve trends of coal samples $01,02,03$, and 04 are similar, with peaks at about 3 to 

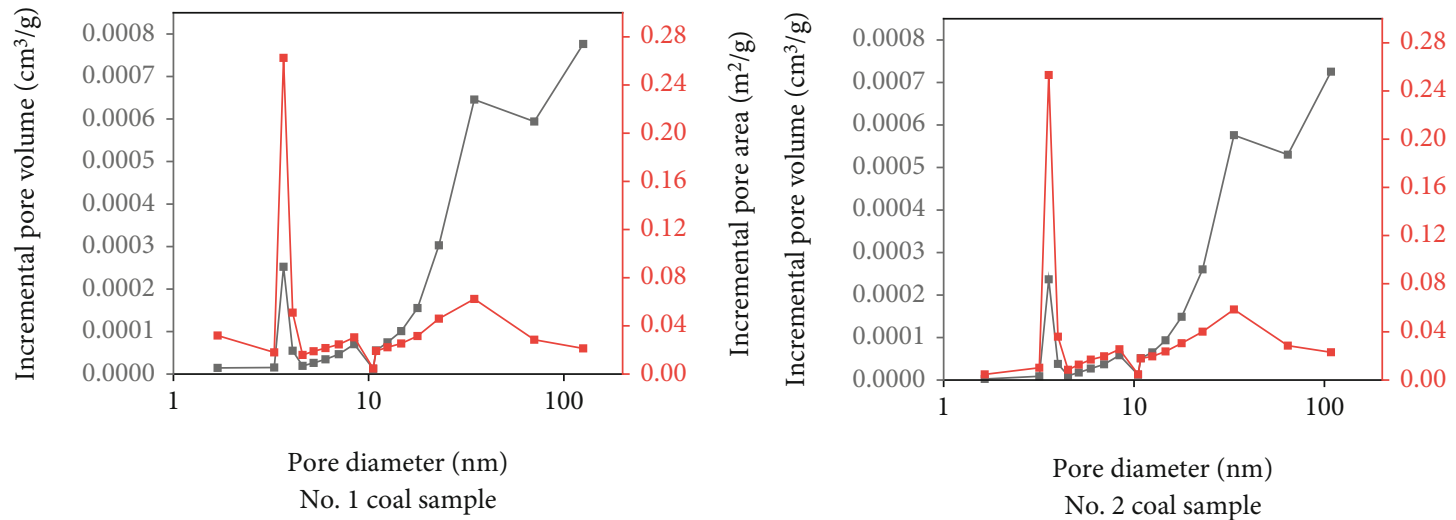

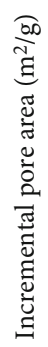

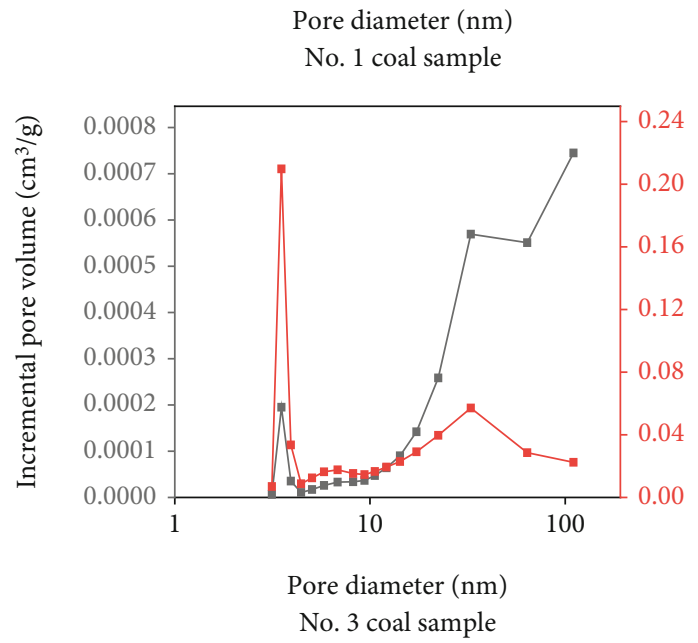

कि

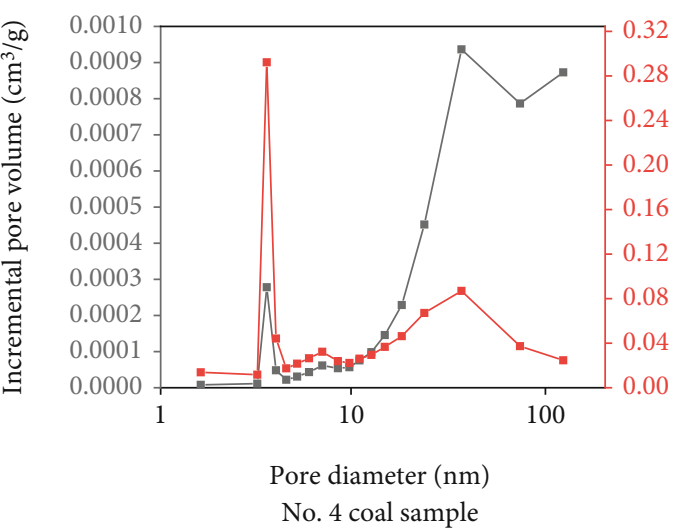

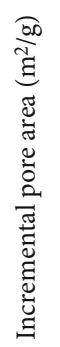

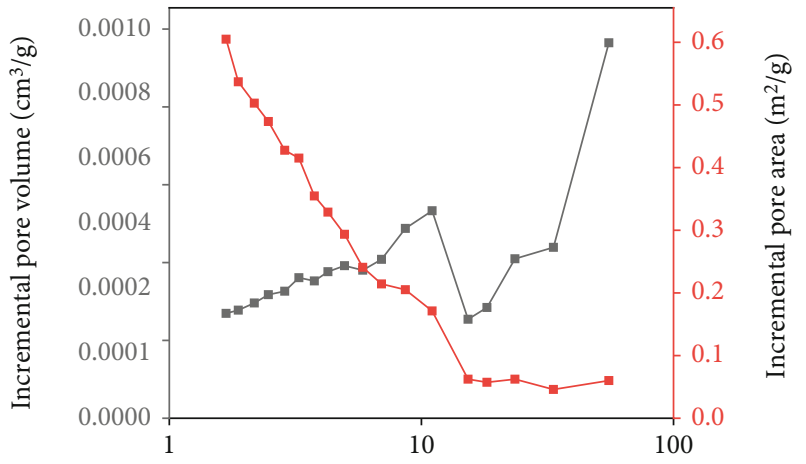

Pore width $(\mathrm{nm})$

No. 5 coal sample

- Pore volume

$\rightarrow$ Pore area

FIGURE 7: Increment diagram of specific surface area and pore volume of coal sample.

$4 \mathrm{~nm}$ and 20 to $40 \mathrm{~nm}$, indicating that micropores and transition pores have a large contribution to the specific surface area of coal samples. However, the curve of coal sample 05 is different from the other four coal samples. As can be seen from the figure, the peak appears at the aperture of about $2 \mathrm{~nm}$, and then it gradually decreases, but it still keeps a large value. After $10 \mathrm{~nm}$, it becomes very low and flattens out, indicating that the micropores within the range of 2 to $10 \mathrm{~nm}$ make a great contribution to the specific surface area of coal samples.

As can be seen from the diagram of the relationship between pore volume increment and pore diameter, the pore volume increment increases continuously with the increase of pore diameter. The peak value of coal samples 01, 02, 03 , and 04 is mostly at the aperture of $30 \mathrm{~nm}$ and $100 \mathrm{~nm}$, while the peak value of coal sample 05 is at $10 \mathrm{~nm}$ and $50 \mathrm{~nm}$, indicating that the transition hole plays a major contribution to the pore volume of coal sample.

4.3. Analysis of Pore Diameter Distribution Characteristics. The classification methods of apertures usually include the B.B. Hodot decimal division and the IUPAC classification. There are many calculation models for apertures, including $\mathrm{BJH}, \mathrm{D}-\mathrm{H}, \mathrm{HK}, \mathrm{DFT}$, and NLDFT. [29] In this paper, the 


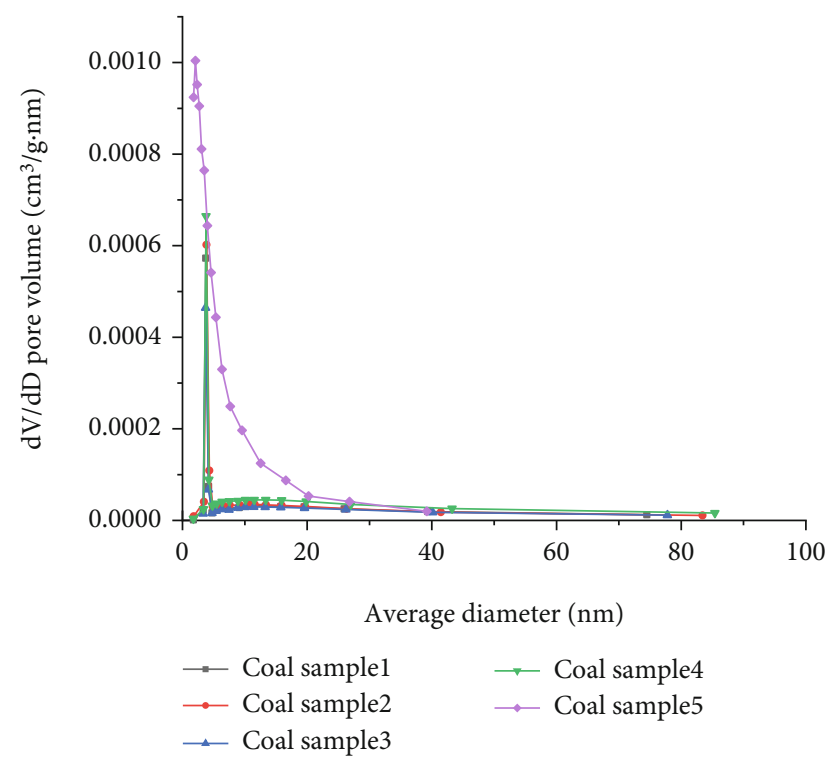

FIGURE 8: Distribution characteristics of pore diameter of a coal sample.

$\mathrm{BJH}$ theoretical model is used for pore diameter analysis of coal samples, and the B.B. Hodot decimal division method [30] is used for the coal pore type division system. According to the classification system, the pore diameters of coal can be divided into four types: macropore $(>1000 \mathrm{~nm})$, mesopore $(100-1000 \mathrm{~nm})$, transition pore $(10-100 \mathrm{~nm})$, and micropore $(<10 \mathrm{~nm})$. The pore diameter distribution range of each sample recorded by the instrument in this experiment is $1.7 \mathrm{~nm}$ to $300 \mathrm{~nm}$. Figure 8 shows the pore diameter distribution characteristics of a coal sample obtained under the low-temperature liquid nitrogen adsorption experiment.

In Figure 8, $d V / d D$ represents the differential of total pore volume to pore diameter, and it represents the distribution function of pore volume density. The peaks protruding from this curve represent the most concentrated pore diameter range in the measured coal sample. As shown in Figure 8, the pore diameter distribution of each coal sample in the region of 2 to $20 \mathrm{~nm}$ presents a single peak distribution phenomenon, which indicates that the pore diameter of a coal sample is mainly distributed in the region of 2 to $20 \mathrm{~nm}$, and the main peak is mainly around 2 to $5 \mathrm{~nm}$. Therefore, the micropores and transition pores larger than $2 \mathrm{~nm}$ contribute greatly to the pore volume. Generally speaking, pores with pore diameter less than $100 \mathrm{~nm}$, especially micropores, are the main factors that determine gas adsorption, storage, and migration. Therefore, the distribution of micropore diameter in coal plays a leading role in gas storage and migration in coal seams.

According to the classification of coal samples according to the low-temperature liquid nitrogen adsorption isotherm above, the pore diameter distribution curve is also divided into two kinds. The peak value of coal samples 1 to 4 appears at around $4 \mathrm{~nm}$, and both ends of the peak value plummet, indicating that the pore diameter distribution is most concentrated when the pore diameter is $4 \mathrm{~nm}$. The curve has a flat trend in the range of 5 to $20 \mathrm{~nm}$, indicating that there are a large number of micropores and transition pores in this range, and the pore diameter distribution is uniform, but there is no particularly concentrated distribution of pores. The peak value of coal sample 05 appears at $2 \mathrm{~nm}$, indicating that the pore diameter distribution is most concentrated at the pore diameter of $2 \mathrm{~nm}$. The curves at both ends of the peak value did not drop suddenly, but the peak value gradually decreased with the increase of pore diameter until $20 \mathrm{~nm}$, indicating that the micropores and transition pores at 2 to $20 \mathrm{~nm}$ accounted for the majority of the coal sample 05. In general, micropores and transition pores play an absolute role in controlling the specific surface area and pore volume of coal samples, respectively.

Table 3 shows the pore diameter distribution and proportion characteristics of coal samples obtained under the low-temperature liquid nitrogen adsorption experiment, and Figure 9 shows the specific surface area and pore volume proportion of each pore diameter segment. It can be seen that the percentage of pore volume in each pore diameter section of a coal sample is dominated by transition pores, and transition pores make the largest contribution to pore volume. Micropore volume accounts for $12.4 \%$ to $61.1 \%$ of the total pore volume, transition pore volume accounts for $25.8 \%$ to $66.2 \%$, and middle pore volume accounts for $13.1 \%$ to $26.1 \%$. The specific surface area of each pore section of a coal sample is dominated by the proportion of micropores, which contributes the most to the specific surface area. The proportion of micropores was $56.2 \%$ to $91.2 \%$, the proportion of transitional pore specific surface area was $7.6 \%$ to $40.87 \%$, and the proportion of middle pore specific surface area was $1.2 \%$ to $3.9 \%$. The results of aperture ratio analysis are consistent with those in Figure 8. The distribution of pore volume in each pore section of a coal sample has the rule that the transition pore is larger than the micropore, and the micropore is larger than the mesopore, and the maximum proportion is $66.2 \%$. The distribution of pore specific surface area show that the micropore is larger than the transition pore, and the transition pores are larger than the mesopores. The maximum ratio is $91.2 \%$.

\section{Discussions}

By comparing the results of scanning electron microscopy of the coal samples in the study area, it can be found that there are metamorphic pores, exogenous pores, and mineral pores in the coal, and there are endogenous fractures, exogenous tensile fractures, and exogenous shear fractures in the coal. This is because the tectonic stress fields or external factors cause different degrees of damage to the coal body, resulting in different types of pore fractures. By comparing the isothermal adsorption curves of coal samples and referring to previous studies and distinguishing from their classification criteria, the analysis shows that the isothermal adsorption curves of coal samples in the study area can be divided into two types, and the pore structure system of coal samples is mainly composed of open pores and impermeable pores closed at one end. This condition is because different holes will produce different hysteretic curves. 
TABLE 3: Characteristics of pore diameter distribution proportion of coal sample.

\begin{tabular}{|c|c|c|c|c|c|c|c|c|}
\hline \multirow{2}{*}{ Coal sample } & \multirow{2}{*}{ Pore volume $\left(\mathrm{cm}^{3} / \mathrm{g}\right)$} & \multicolumn{3}{|c|}{ Pore size ratio (\%) } & \multirow{2}{*}{ Surface area $\left(\mathrm{m}^{2} / \mathrm{g}\right)$} & \multicolumn{3}{|c|}{ Pore size ratio (\%) } \\
\hline & & $<10 \mathrm{~nm}$ & $10 \sim 100 \mathrm{~nm}$ & $>100 \mathrm{~nm}$ & & $<10 \mathrm{~nm}$ & $10 \sim 100 \mathrm{~nm}$ & $>100 \mathrm{~nm}$ \\
\hline 1 & 0.002967 & 15 & 60 & 25 & 0.3699 & 61.1 & 35.3 & 3.6 \\
\hline 2 & 0.003224 & 16.4 & 59.7 & 23.9 & 0.4405 & 64.5 & 32.6 & 2.9 \\
\hline 3 & 0.002865 & 12.4 & 61.5 & 26.1 & 0.2810 & 56.2 & 39.9 & 3.9 \\
\hline 4 & 0.004229 & 12.92 & 66.2 & 20.9 & 0.5509 & 56.3 & 40.9 & 2.8 \\
\hline 5 & 0.007375 & 61.1 & 25.8 & 13.1 & 4.7569 & 91.2 & 7.6 & 1.2 \\
\hline
\end{tabular}

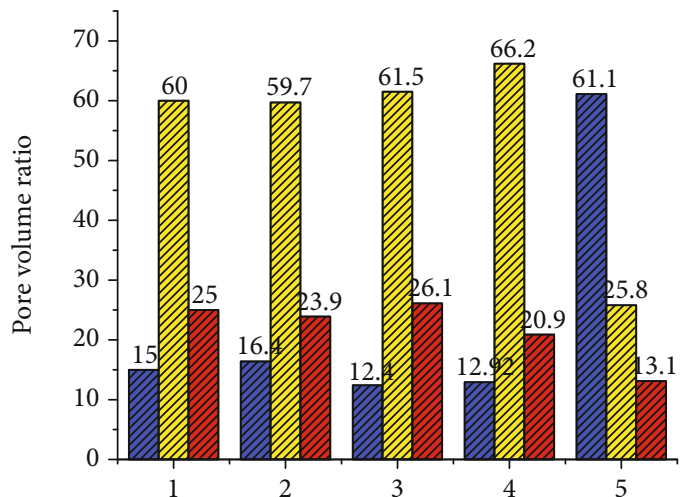

Coal sample

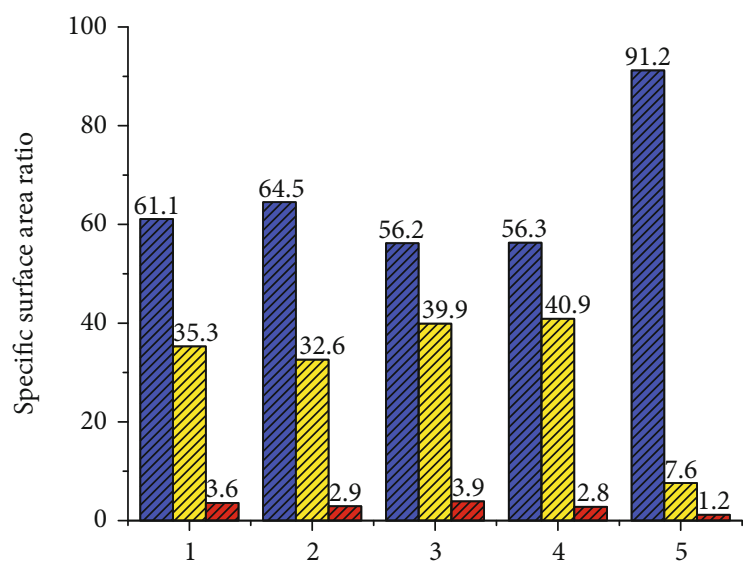

Coal sample

mIn $<10 \mathrm{~nm}$

WIIt $10 \sim 100 \mathrm{~nm}$

IIIS $>100 \mathrm{~nm}$

Figure 9: Specific surface area and pore volume ratio of each pore diameter segment of a coal sample.

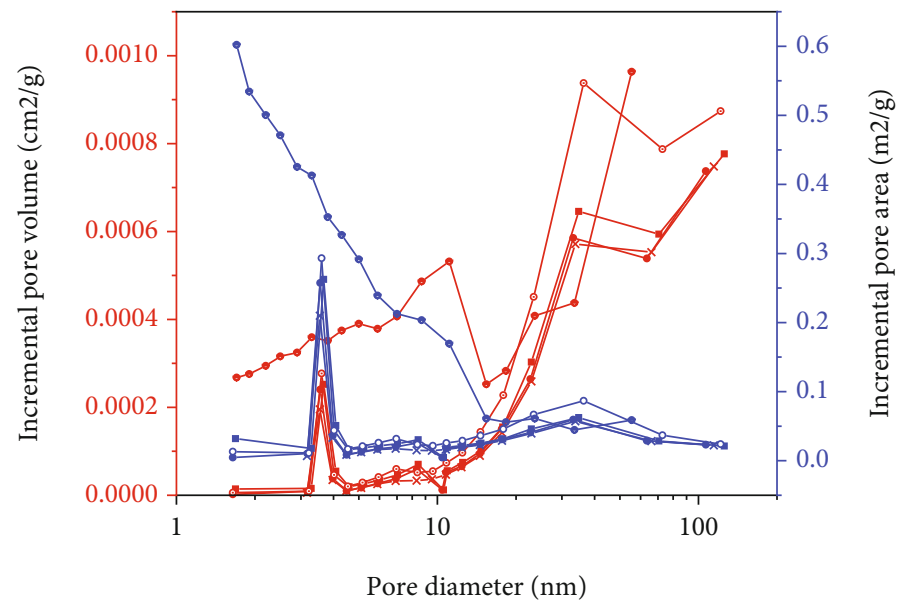

Pore diameter $(\mathrm{nm})$

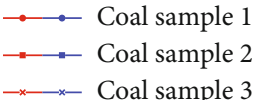

$\multimap$ Coal sample 4

Coal sample 5

FIGURE 10: Distribution trend of specific surface area and pore volume of coal sample.

According to Figure 10, qualitative analysis was made on the variation of specific surface area and pore volume with pore diameter of coal samples in the study area. It can be seen from the overall trend of the relation curve between incremental pore area and pore diameter that there are different peaks in the range of the pore diameter of coal, especially in the range of a micropore, indicating that a micropore has a large contribution to the specific surface 

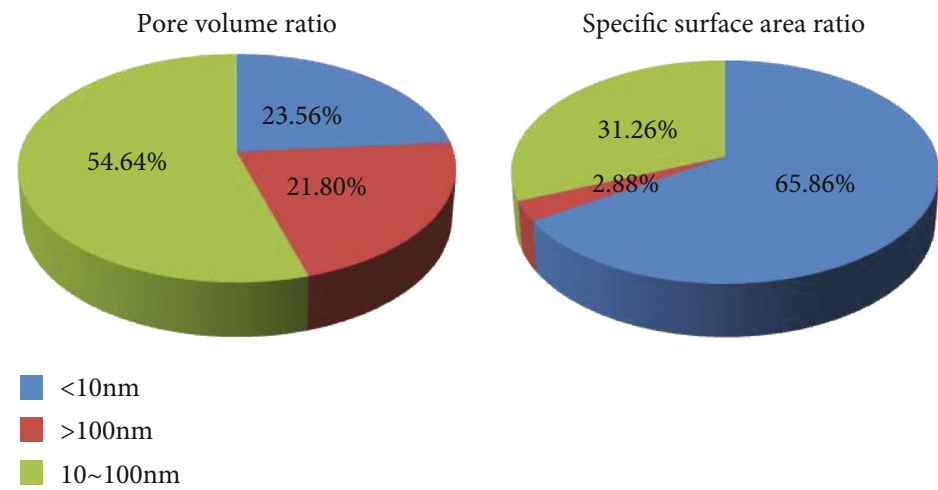

Figure 11: Figure of average proportion of specific surface area and pore volume of coal sample.

area of a coal sample, accounting for the largest proportion. From the overall trend of the relation curve between incremental pore volume and pore diameter, it can be seen that the incremental pore volume increases with the increase of pore diameter and presents the characteristics of multipeak distribution. The most obvious peak value is mostly located within the range of the transition hole, indicating that the transition hole plays a major contribution to the pore volume of a coal sample and accounts for the largest proportion.

On the basis of qualitative analysis, quantitative analysis was carried out on the average proportion of specific surface area and pore volume of each pore section of coal sample. As can be seen from Figure 11, the micropores accounted for $23.56 \%$ of the total pore volume, the transition pores accounted for $21.80 \%$, and the mesopores accounted for $54.64 \%$. The specific surface area of micropores, transition pores, and mesopores accounted for $65.86 \%, 31.26 \%$, and $2.88 \%$, respectively. The results show that the distribution of pore volume in each pore section of a coal sample has the rule that the transition pore is larger than the micropore, and the micropore is larger than the mesopore. The distribution of the pore specific surface area has the rule that the micropore is larger than the transition pore, and the transition pore is larger than the mesopore. This is because micropores and transition pores make major contributions to the pore specific surface area and pore volume of coal samples, respectively, and the greater the contribution, the greater the proportion. The research results have certain practical significance for the design of gas extraction, coal seam mining, and migration in the study area.

\section{Conclusion}

(1) SEM results show that there are three types of pores, namely, metamorphic pores, exogenous pores, and mineral pores, and there are five subtypes of pores with different genetic types, such as air vent, granular hole, breccia pores, friction pores, and intergranular pores. The pore diameter is generally in the transition range from nanometer to micron. There are endogenous fractures, exogenous tensile fractures, and exogenous shear fractures developed in the coal body. The overall development is relatively compact and flat. The research on fractures is on the micron scale, generally ranging from a few to dozens of microns

(2) The low-temperature liquid nitrogen adsorption experiments show that there are two main types of hysteresis curve. The I type curve produces a loop. A "hysteresis loop" is obvious, and an inflection point appears, but it is not obvious. The II type curve does not produce an adsorption back line and has no obvious inflection point. The pores of coal samples are mainly composed of open pores and impermeable holes closed at one end. The average pore diameter is $16.0313 \mathrm{~nm}$, and the pore specific surface area and total pore volume are small, averaging $1.27984 \mathrm{~m}^{2} / \mathrm{g}$ and $0.0041246 \mathrm{~cm}^{3} / \mathrm{g}$, respectively

(3) The pore specific surface area and pore volume of coal are mainly contributed by micropores and transition pores at 2 to $20 \mathrm{~nm}$. The distribution of pore volume in each pore section of a coal sample has the rule that the transition pore is larger than the micropore, and the micropore is larger than the mesopore, and the maximum ratio is $66.2 \%$. The distribution of specific surface area has the rule that the micropore is larger than the transition pore, and the transition pore is larger than the mesopore, and the maximum ratio is $91.2 \%$.

\section{Data Availability}

The data used to support the findings of this study have not been made available because the original data relate to the intellectual property rights of the author, and all the original data cannot appear in the paper, and the experimental data that cannot appear is related to privacy.

\section{Conflicts of Interest}

All authors declare no conflict of interest.

\section{Acknowledgments}

This work was supported by the Key Project of Hubei Province Education Department (D20201506), the Postdoctoral 
Innovation Project of Hebei Province (No. B2019005005), and the Wuhan Institute of Technology Science Fund (No. K201855).

\section{References}

[1] S. Zhou, D. Liu, Y. Cai, Z. Karpyn, and Y. Yao, "Petrographic controls on pore and fissure characteristics of coals from the southern Junggar Coalfield, Northwest China," Energies, vol. 11, no. 6, p. 1556, 2018.

[2] J. Huang, G. Hu, G. Xu, B. Nie, N. Yang, and J. Xu, “The development of microstructure of coal by microwave irradiation stimulation," Journal of Natural Gas Science and Engineering, vol. 66, pp. 86-95, 2019.

[3] M. Zhang, M. Lin, H. Zhu, D. Zhou, and L. Wang, "An experimental study of the damage characteristics of gas-containing coal under the conditions of different loading and unloading rates," Journal of Loss Prevention in the Process Industries, vol. 55, pp. 338-346, 2018.

[4] L. Guannan, Y. Dayu, Y. Boming, G. Feng, and C. Peijian, “A study on gas drainage considering coupling process of fracture-pore microstructure and coal deformation," Fractals, vol. 29, no. 2, 2021.

[5] H. Gan, S. P. Nandi, and P. L. Walker Jr., "Nature of the porosity in American coals," Fuel, vol. 51, no. 4, pp. 272-277, 1972.

[6] S. Liu, D. Wang, G. Yin, M. Li, and X. Li, "Experimental study on the microstructure evolution laws in coal seam affected by temperature impact," Rock Mechanics and Rock Engineering, vol. 53, 2020.

[7] Q. Cheng, B. Huang, and Z. Li, "Research progress of experimental methods for pore fractures in coal and rock mass," China Mining Industry, vol. 21, no. 1, pp. 115-118, 2012.

[8] Z. Liwei, Analysis of Pore Structure and Controlling Factors of Coal Reservoir in Xishanyao Formation, Santanghu Basin, [M.S. thesis], China University of Geosciences, 2019.

[9] L. Qin, C. Zhai, J. Xu, S. Liu, C. Zhong, and G. Yu, "Evolution of the pore structure in coal subjected to freeze-thaw using liquid nitrogen to enhance coalbed methane extraction," Journal of Petroleum Science and Engineering, vol. 175, pp. 129-139, 2019.

[10] W. Li, H. Yao, H. Liu, Z. Kang, X. Song, and Z. Feng, "Threedimensional pore fine characterization of coal with different coal structure based on microscopic CT," Journal of China Coal Society, vol. 39, no. 6, pp. 1127-1132, 2014.

[11] Q. Meng, Y. Zhao, Y. Hu, Z. Feng, and Y. Yu, "Experimental study on pore structure morphology of coking coal," Journal of China Coal Society, vol. 36, no. 3, pp. 487-490, 2011.

[12] A. H. Thompson, A. J. Katz, and C. E. Krohn, "The microgeometry and transport properties of sedimentary rock," Advances in Physics, vol. 36, no. 5, pp. 625-694, 1987.

[13] B. H. Kueper and E. O. Frind, "Two-phase flow in heterogeneous porous media: 1 . Model development," Water resources research, vol. 27, no. 6, pp. 1049-1057, 1991.

[14] F. Wang, Y. Cheng, S. Lu, K. Jin, and W. Zhao, "Influence of coalification on the pore characteristics of middle-high rank coal," Energy \& Fuels, vol. 28, no. 9, pp. 5729-5736, 2014.

[15] B. Nie, X. Liu, L. Yang, J. Meng, and X. Li, "Pore structure characterization of different rank coals using gas adsorption and scanning electron microscopy," Fuel, vol. 158, no. 15, pp. 908-917, 2015.
[16] M. M. Mahamud López, "Textural characterization of active carbons using fractal analysis," Fuel Processing Technology, vol. 87, no. 10, 2006.

[17] Y. D. Cai, D. M. Liu, Z. J. Pan, Y. B. Yao, J. Q. Li, and Y. K. Qiu, "Pore structure of selected Chinese coals with heating and pressurization treatments," Science China Earth Sciences, vol. 57, no. 7, pp. 1567-1582, 2014.

[18] A. Y. Klimenko, D. N. Saulov, P. Massarotto, and V. Rudolph, "Conditional model for sorption in porous media with fractal properties," Transport in Porous Media, vol. 92, no. 3, pp. 745-765, 2012.

[19] X. Li, Z. Li, L. Zhang, J. Gao, B. Nie, and Y. Meng, "Characterization of pore structure of coal samples with different coal rank and its influence on gas desorption and diffusion," Journal of China Coal Society, vol. 44, no. S1, pp. 142-156, 2019.

[20] W. Jiang, X. Song, and L. Zhong, "Pore characteristics of coal with different coal structure and its influence on gas outburst based on low temperature liquid nitrogen experiment," Journal of China Coal Society, vol. 36, no. 4, pp. 609-614, 2011.

[21] Y. Sun, "Experimental study on the influence of preoxidation on specific surface area and pore diameter distribution of coal," Coal Mine Safety, vol. 51, no. 10, 2020.

[22] T. Li and H. Wang, "Study on pore structure characteristics of low-rank coal under different detemperatures-taking lignite from Xishanyao Formation, Turpan-Hami Basin, Xinjiang as an example [J/OL]," Journal of China Coal Society, 2010.

[23] Y. Li, Y. Zhang, L. Zhang, and J. Hou, "Characterization of pore structure of coal based on mercury injection, low temperature $\mathrm{N}_{2}$ adsorption and $\mathrm{CO}_{2}$ adsorption," Journal of China Coal Society, vol. 44, no. 4, pp. 1188-1196, 2019.

[24] I. Ammosov and I. V. Eremin, Fissuring in Coal, IZDAT Publishers Moscow, Office Technical Services, Washington, DC, USA, 1963.

[25] Y. Zeng, Y. Qu, and J. Song, "Fracture system of coal seam and its influence on coalbed methane production," Journal of Geology, vol. 24, no. 2, pp. 91-94, 2000.

[26] X. Fu, Y. Qin, and C. W, Coal Bed Methane Geology, Xuzhou: China University of Mining and Technology Press, China, 2007.

[27] P. Chen and X. Tang, "Study on low-temperature nitrogen adsorption method and characteristics of micropores in coal," Journal of China Coal Society, vol. 26, no. 5, pp. 552-556, 2001.

[28] S. Brunauer, P. H. Emmett, and E. Teller, "Adsorption of gases in multimolecular layers," Journal of the American Chemical Society, vol. 60, no. 2, pp. 309-319, 1938.

[29] M. Thommes, "Physisorption of gases, with special reference to the evaluation of surface area and pore size distribution (IUPAC technical report)," Chemistry International the News Magazine of IUPAC, vol. 38, no. 1, p. 25, 2016.

[30] B. B. Hodot, Outburst of Coal and Coalbed Gas, China Industry Press, Beijing, China, 1966. 